\title{
Veterinary Contributions to Wildlife Biology: Participation in Avian Field Studies in Alaska
}

\author{
Laurel A. Degernes, DVM, MPH, Dipl ABVP (Avian)
}

\begin{abstract}
This report describes the author's experiences in participating in avian research during 3 field seasons in remote areas in Prince William Sound (PWS), located in south-central Alaska. Veterinary support was needed to biopsy the livers of nestling and adult pigeon guillemots (Cepphus columba) and adult black oystercatchers (Haematopus bachmani). These surgeries were part of larger research studies investigating guillemot and oystercatcher populations and possible continued exposure to residual crude oil in the marine environment after the Exxon Valdez oil spill in PWS in 1989.
\end{abstract}

\section{Introduction}

As an undergraduate biology student, I became an avid bird watcher and had dreams of becoming a wildlife biologist someday. Those dreams took a different route when I was successful in getting accepted into veterinary school and unsuccessful in getting into any of the wildlife biology graduate programs to which I had applied. I followed a conventional path through veterinary school and during 4 years of private practice experience in mixed and small animal practices. I finally had an opportunity to combine my interests in birds, wildlife biology, and veterinary medicine when I started working at The Raptor Center at the University of Minnesota, and I very quickly recognized that avian medicine was my true calling. I feel quite fortunate to have been able to focus my career on avian medicine and surgery for the past 21 years, 16 of which have been at the College of Veterinary Medicine at North Carolina State University (NCSU-CVM).

In the spring of 1998, I was contacted by Dr Daniel Mulcahy, wildlife veterinarian with the US Geological Survey, to see if I was available to

Caveat: This article was written from the viewpoint of one person involved in multiagency field research studies and is not intended to provide a complete synopsis of each project, nor does it reflect the views of the US Geological Survey, the US Fish and Wildlife Service, or the Exxon Valdez Oil Spill Trustee Council.

From the Department of Clinical Sciences, College of Veterinary Medicine, North Carolina State University, 4700 Hillsborough St, Raleigh, NC 27606, USA. assist a group of wildlife biologists who were studying pigeon guillemots (Cepphus columba) in Prince William Sound (PWS), in south-central Alaska. Normally, Dan would have provided veterinary support for this project, but he already had other scheduled field projects. Specifically, they needed a veterinarian to perform liver biopsies in guillemot chicks to test for hepatic cytochrome $\mathrm{P}_{450} 1 \mathrm{~A}$, a biomarker for exposure to crude oil from food sources. A team of biologists, lead by Dr Greg Golet with the US Fish and Wildlife Service, was studying a declining population of pigeon guillemots in an area that was heavily oiled after the Exxon Valdez oil spill in March 1989. ${ }^{1}$ Thus, lethal sampling to obtain liver samples was not an acceptable option with these birds. I readily accepted the opportunity to participate in this project because I was confident in my surgical skills and relished the chance to visit this area of Alaska. In July 1998, we took liver biopsy samples in chicks from sites that were previously oiled and nonoiled (control). The next June, I returned to participate in a continuation of this project; but, this time, liver biopsies were done in adult pigeon guillemots. A third liver biopsy project was done in May 2004 in PWS with a different species, the black oystercatcher (Haematopus bachmani). This article is a compilation of my experiences during these 3 projects.

\section{Logistical Preparation}

Any field research in remote areas of Alaska (Fig 1) requires extensive advance planning and 


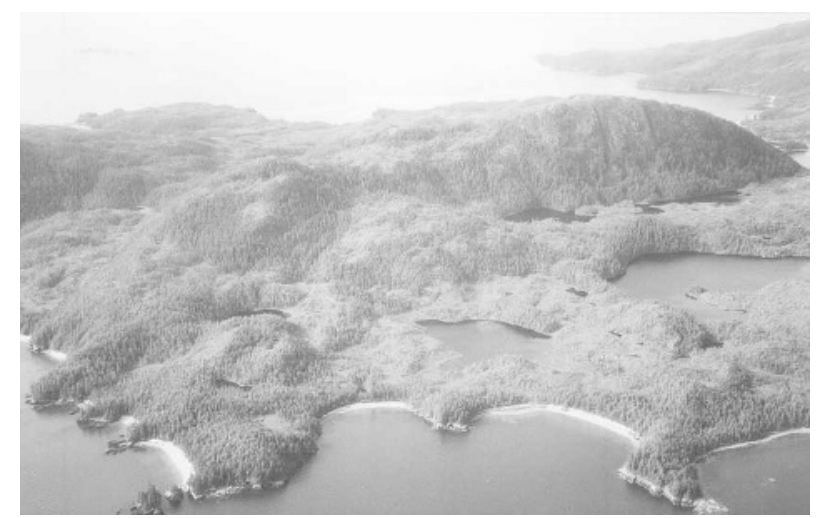

Figure 1. Typical island terrain in the middle of Prince William Sound, where the guillemot project was conducted.

organization. In our case, the nearest coastal town, Valdez, was at least a half-day boat ride away, and Anchorage, the largest city in Alaska, required a half-day boat ride, a train ride through a tunnel through the mountains, and another 1.5hour drive by car, not exactly an easy run to town for a gallon of milk or a forgotten surgical item! Fortunately for me, the field biologists were experienced with logistical preparation for an extended field season, and Dan Mulcahy was superbly organized for preparing for remote field anesthesia and surgery projects. All of the very careful planning and execution was done long before I flew up to Alaska and certainly made my experience go more smoothly. Every detail was carefully planned so that all anesthesia, surgery, and supportive care supplies and equipment were available. In addition, Dan and his wife, Celia, graciously hosted and entertained me before each trip into PWS, and I usually combined a visit before or after a field project with my twin sister who lives on the Kenai Peninsula in south-central Alaska.

I vividly recall a conversation that I had with Dan concerning veterinarians working with wildlife biologists, and how there have been strained relationships in the past when egos got in the way of the 2 groups working together as a united team. Basically, the clear message was that each group has important contributions to bring to a project, none of which are more or less important to the overall success. In other words, veterinarians and biologists each have their areas of expertise, and veterinarians should not presume that they know more than biologists about a particular species. In addition, each group needs to be able to clearly communicate requests, concerns, and priorities to the other, and to respect each person's role in a project. I always kept this message in mind whenever I met a new group of field biologists and was oriented to their projects. As fate would have it, I found this message to be particularly useful during my first surgery field project.

\section{The First Field Season: Pigeon Guillemot Nestling Surgeries}

We worked at 2 different field sites in PWS. Naked Island, in the middle of PWS, was a site that was heavily oiled after the Exxon Valdez oil spill in 1989. The nonoiled, control site was located near Jackpot Island/Icy Bay on the western side of PWS. The wildlife biologists, under the leadership of Dr Greg Golet, had been in the field for more than 6 weeks by the time we arrived on Naked Island via float plane from Anchorage. I flew out with Kim Trust, a toxicologist with the US Fish and Wildlife Service, who served as the anesthetist on this project (Kim had worked with Dan Mulcahy as an anesthetist for another avian surgery project). During the first couple of days on Naked Island, the biologists felt that the chicks were not quite old enough to start doing surgeries, so I volunteered to assist them with their field observations and nest checks. What an opportunity to observe the birds and learn from these biologists! I quickly picked up on their anxiety about the planned surgeries on "their chicks." The summer of 1998 had proven to be a rough year for chicks, because nearly two thirds of the 95 active nests had been lost because of storms (flooded nest crevices), and chick and adult predation by introduced mink, a predator that was not a natural part of that island's ecosystem. ${ }^{1}$ No one knew what potential problems could arise from our interfering with the chicks. Would the parents abandon the chicks after surgery? Would the chicks have complications, such as hemorrhage, infection, or poor growth? Would the chicks survive the anesthesia and the surgery? And last, but certainly not least, would the biologists have confidence in the veterinarian (me) knowing how to do the surgery in a species that she had never anesthetized before, done surgery on, and had never even handled before!? These were the questions and concerns that circulated verbally and unspoken for the first 2.5 days that I was in camp. Finally, we decided to do a trial run with 2 chicks from a single nest, and if they survived surgery and seemed to be doing well 2 days after surgery, then, maybe, just 


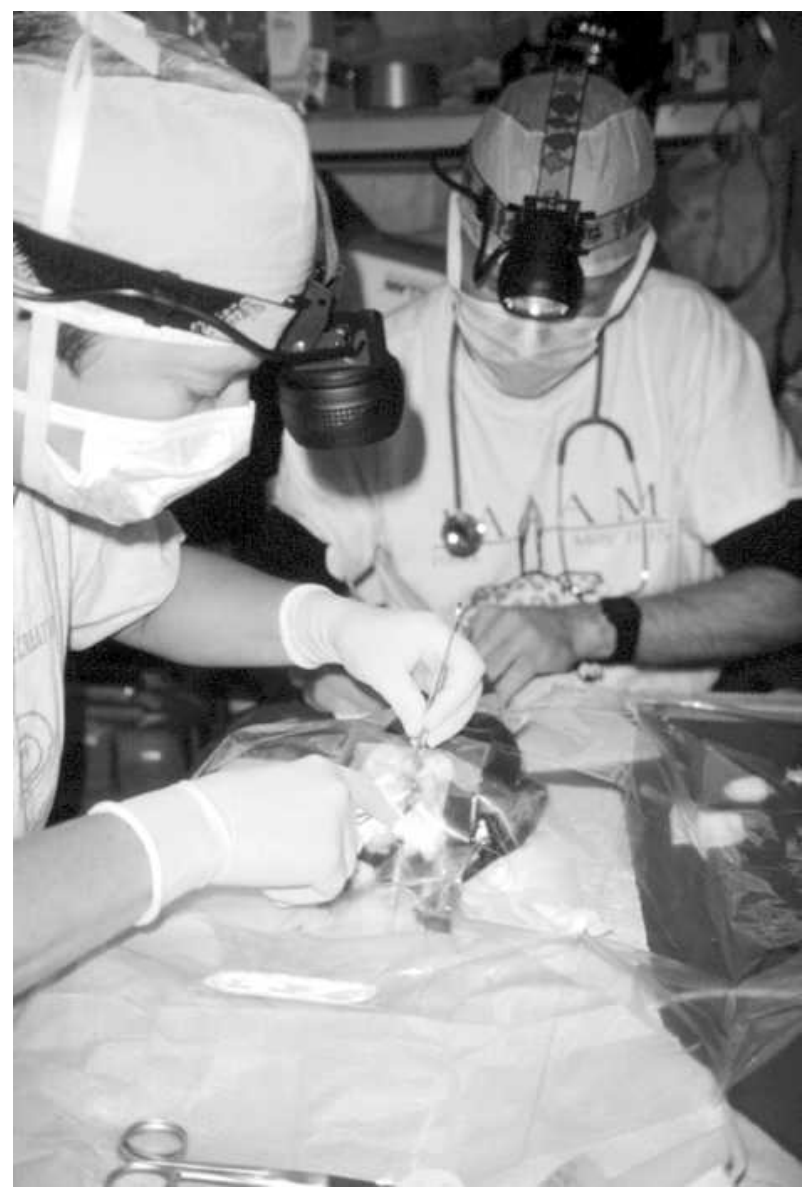

Figure 2. View of the setup for guillemot liver biopsy procedure. The author is collecting a liver biopsy sample from an adult pigeon guillemot, while Dr Craig Harms is monitoring anesthesia.

maybe, we would proceed from there. I must say that I was extremely relieved that the first pair of chicks did quite well during anesthesia and surgery and were gaining weight and thriving when checked 2 days later. Whew! I passed the first test and, from there, the rest was easy by comparison. Kim and I made a great team, and, during the 9 days that I was in PWS, we did liver biopsies in 26 chicks, including 14 from the previously oiled area on and near Naked Island and 12 from the nonoiled location near Jackpot Island/Icy Bay (Fig 2). On one particularly busy day, we did 11 surgeries but, more typically, we did 3 to 5 surgeries per day. The chicks were between 18 and 24 days of age and were collected from known nest sites. After the biopsy samples were taken, the chicks were returned as soon as possible to the nest (usually within 1 to 3 hours, depending on how close the nest site was from the field camp). A biologist remained at the nest site in a visible location while the

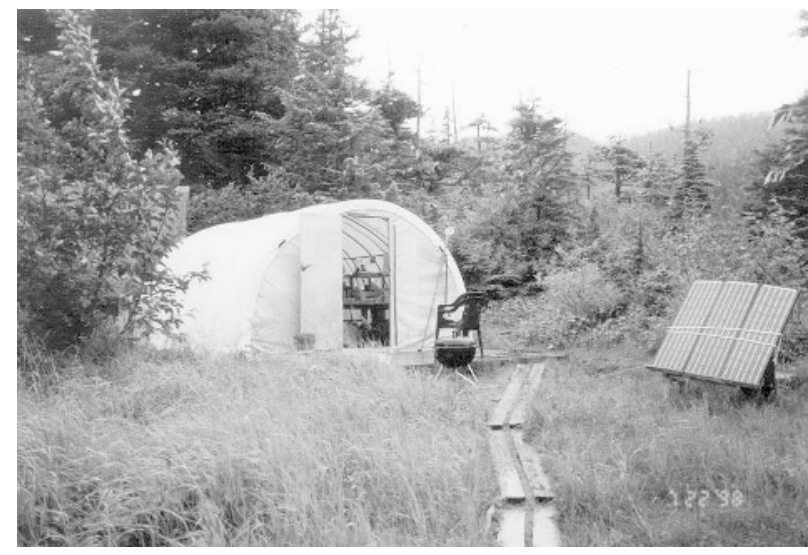

Figure 3. View of the kitchen Weatherport and solar panels on Naked Island in Prince William Sound. This was one of the field camps (previously oiled site) for 2 seasons of pigeon guillemot surgeries.

chicks were absent, to discourage the adults from returning to the nest and finding it empty. All chicks survived the surgery, and none were abandoned after surgery as a result of our actions, although 4 chicks were predated in the nest before fledging. ${ }^{2}$ Once the chicks fledged, further follow-up was not possible.

\section{The Field Camp Arrangements}

It was interesting to see how the biologists set up the field camps at the 2 locations in PWS. There were separate teams of biologists at Naked Island and Jackpot Island/Icy Bay. Both sites were located on US Forest Service land and were set up as temporary field camps for the summer season, with most of the supplies sent out by a barge in the spring. The terrain at Naked Island was fairly wet, so a series of wooden boardwalks were placed to minimize environmental impact. In addition, several Quonset hut-like "Weatherports" (Hansen Weatherport, Delta, CO, USA) were set up with plywood floors, to provide a camp kitchen, a storage building, and a laboratory/surgery building (Fig 3). The summer was often rainy and cool, so it was helpful to have a shelter to work in that was mostly mosquitofree. Sleeping accommodations consisted of small tents set up under the alders above the high-tide line, with a great view of Cabin Bay and its resident sea otters! The camp setup at Jackpot Bay was similar, but with a smaller crew, their "buildings" consisted of a smaller kitchen Weatherport and a large canvas tent for storage/surgery, plus tents on platforms for sleeping. I have been a camper all of my life, so the accommodations were just fine, and the views were unsurpassed! 


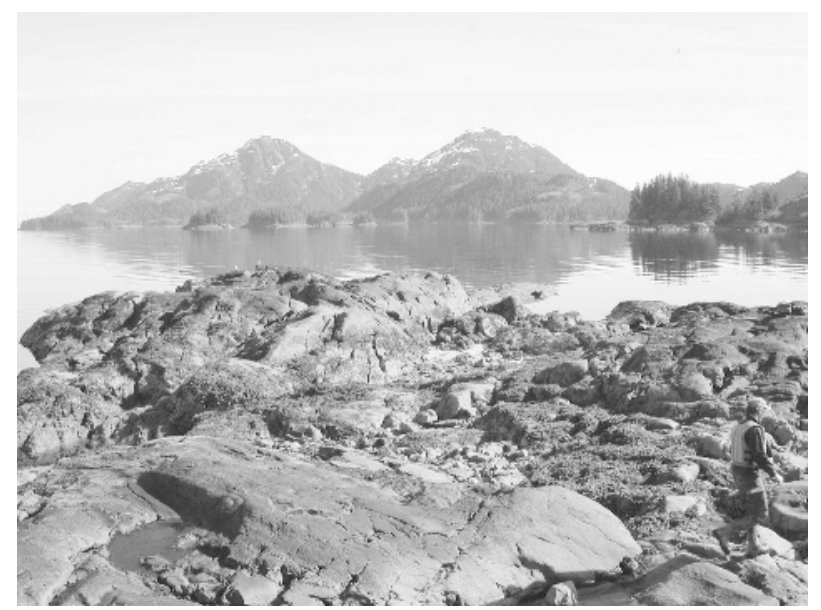

Figure 4. Typical terrain for black oystercatcher nest sites, in the rocky area in the foreground, just above the high-tide line (above the vegetation-covered rocks in the background that are only visible at low tide).

The "surgical suite" was rustic but fully functional. Surgeries were done on a folding or plywood table, lighting was provided with wellaimed head lamps, and heat was provided (at least for the birds) with warmed water in sealed bags placed next to the bodies and over the feet and legs. The ambient temperature in the weather port or canvas tent was approximately $12-18^{\circ} \mathrm{C}$ $\left(55-65^{\circ} \mathrm{F}\right)$. We used portable isoflurane anesthesia machines and, for monitoring, a stethoscope, an ultrasonic Doppler flow monitor, capnography, and cloacal temperature probe. Each surgery was done with a sterile transparent drape and surgical pack. A more detailed description of the surgical procedures, heart and respiratory rates, body temperature, and anesthesia complications was previously published for the pigeon guillemot project. $^{2}$

\section{The Second Field Season: Adult Pigeon Guillemot Surgeries}

The second year of the pigeon guillemot field surgery project was a continuation of the first season, except that biopsy samples were collected from adult birds over a 2-week period during nesting season. This season was easier in some respects and more difficult in other ways. First, I had already gained the respect and the confidence of the biologists, and we had developed a great partnership in working together with the birds. But, we still had concerns about how well the adults would do with anesthesia and surgery, and catching adult birds proved to be very challenging compared with catching the chicks the first year. The project was done during nesting season when

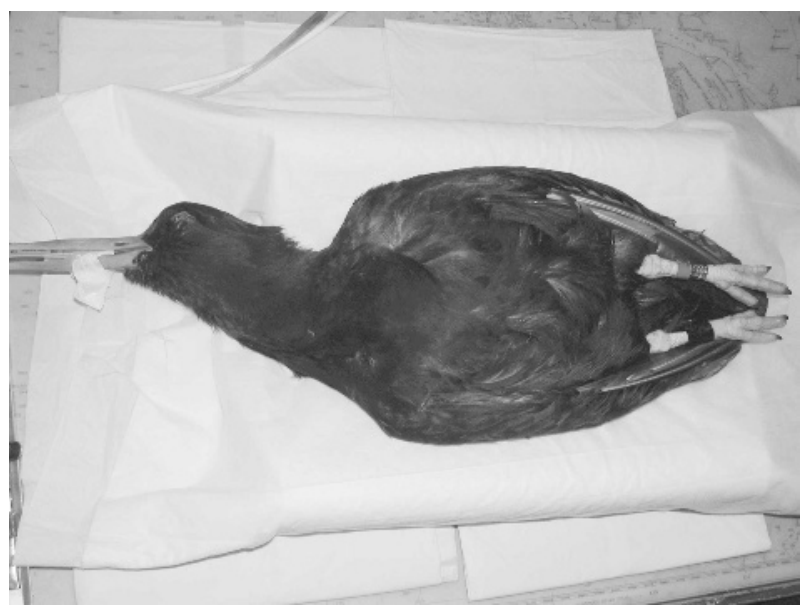

Figure 5. An adult black oystercatcher anesthetized with isoflurane, intubated, and ready for surgical preparation for liver biopsy.

both adults were sharing incubation duties. Various strategies that had been used in the past for capturing adults were not successful that year, including, for example, mist nets, noose mats, and rocket nets. Ultimately, what worked most often was the biologist quietly approaching the nest cavity (usually on a rocky cliff, tucked into rock crevices or under tree roots; Fig 4), and catching the adult as it flushed off the nest with a small fishing net. Whenever possible, both adults from a nesting pair were caught to minimize the number of nest disturbances. Typically, after the first bird was caught off the nest, it did not return to the nest after the biopsy procedure, but its mate was often incubating the eggs when the biologists returned later the same day, or the next morning. The biologists were fairly confident that the adults would abandon the nests after such a major disturbance. Therefore, eggs were collected after both adults were captured for biopsy or once it was determined that the nest was abandoned. The eggs were artificially incubated in the field until they were transferred to the Alaska SeaLife Center in Seward, Alaska, for hatching and rearing. In the second year of the study, biopsy samples were taken from 13 adults at the Naked Island (oiled) site and from 11 adults at the Jackpot Island/Icy Bay (nonoiled) site. All birds survived the surgery and the anesthesia, thanks in large part to my colleague from NCSU-CVM, Dr Craig Harms, who provided all of the anesthesia support for the birds. The adults were more challenging anesthesia candidates than the juveniles, ${ }^{2}$ and I really appreciated teaming up with another experienced veterinarian. One year after surgery, 10 of 11 birds from Jackpot Island/Icy Bay were resighted, and 2 


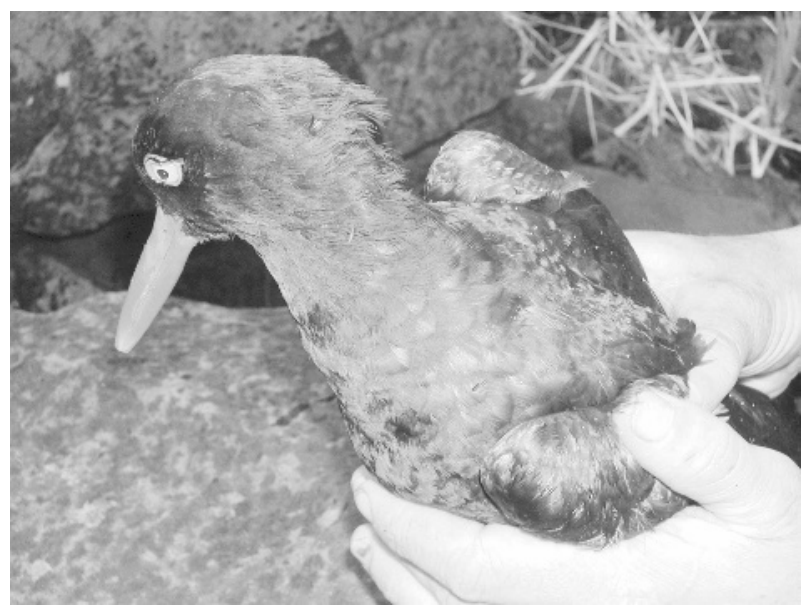

Figure 6. An adult black oystercatcher ready for release at its nesting territory, after liver biopsy was completed.

of 13 birds from Naked Island were resighted (overall nesting attempts on Naked Island in summer 2000 were reduced, likely a result of continued mink predation problems). ${ }^{2}$

\section{The Third Field Season: Black Oystercatcher Surgeries}

In May 2004, I had a third opportunity to return to PWS, Alaska, this time working with black oystercatchers. I teamed up with Dr Terra Kelly from NCSU-CVM, who was in the last year of her zoological medicine residency program. Again, there were similarities and differences with this field season compared with earlier seasons. The surgery was essentially the same, although it was much easier to biopsy the liver in oystercatchers than adult guillemots, because their keels were not as elongated. Anesthesia was less complicated as well, because oystercatchers did not undergo a dive response with profound bradycardia like adult guillemots (Fig 5). Even some of the biologists were the same. I was happy to work with Kelsey Sullivan and Ali McKnight for the third season, and the rest of the biologists were also great to work with, led by lead biologist, Dr Richard Lanctot. And yes, we had the same initial concerns about how well the adult nesting oystercatchers would do during anesthesia and surgery, and how they would behave after release. Would they abandon their nests or resume incubation?

What was really interesting and amazing was how well the oystercatchers did after surgery. We found that they remained calm if we used a cloth "hood" made from a soft cotton sock with a small hole for the bill to protrude. We usually returned

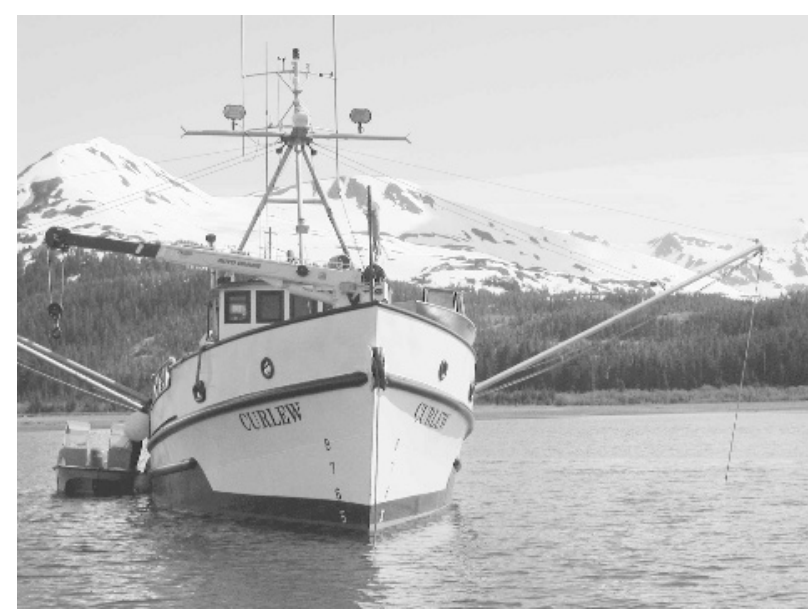

Figure 7. The US Fish and Wildlife Service research vessel, the $M / V$ Curlew, moored in a protected bay off Montague Island, on the eastern side of Prince William Sound. The Curlew was the base camp for the oystercatcher project.

the oystercatcher to its nest site within 1 to 2 hours after completing the surgery (Fig 6), and the bird generally flew around, vocalizing and interacting with its mate. Even more amazing was that the birds did not automatically abandon their nests. A small follow-up survey in June 2004 done by biologists with the US Forest Service documented successful hatching of at least 1 chick from 3 of 9 pairs of oystercatchers, where at least 1 of the adults had been sampled.

Catching adult black oystercatchers proved to be a major challenge, and the biologists tried different methods. A typical nest site was a small gravel depression among the rocks, usually just above high tide on a rocky outcrop. The most successful methods were by using either a small leg noose to catch an adult after it returned to incubate its eggs or mist nets set up near a nest site. Over the course of 10 days, we performed liver biopsies in 28 adults: 18 from sites previously oiled (Knight and Green Islands) and 10 from nonoiled sites (Montague Island). All birds did well under anesthesia, and we did not have any surgical complications.

\section{The Oystercatcher Field Camp: Life Onboard the MIV Curlew}

Our base camp for this trip was on a US Fish and Wildlife Service vessel, the $M / V$ Curlew, captained by Joe McClung, a very experienced captain and a great cook! The Curlew was a $65-\mathrm{ft}$ (19.8-m) refurbished military troop transport vessel from the Korean War era and had pretty basic accommodations (Fig 7). We set up our 
"surgical suite" on a small table in the bunk room below deck, which worked out quite well. Lighting and environmental temperatures were better than in the field camps for the guillemot projects; but, because both Terra and I are susceptible to motion sickness, it was imperative to moor the boat in calm, protected waters for surgeries. We often had time between surgeries to row a small inflatable boat to shore and take a hike while the biologists were catching birds. We also helped with some of the bird captures, which was a great way to learn more about the natural history of oystercatchers and to get to know the biologists.

The knowledge and skills possessed by the biologists was impressive. They not only needed to be expert field biologists and astute observers but also accomplished rock climbers and boat captains. Everyone involved with the projects worked tirelessly and had a great attitude toward their work and compassion for the welfare of the birds. There are many potential opportunities for veterinarians to get involved with wildlife research studies, and it is important to develop a cooperative, mutually beneficial working relationship with the biologists. It is also important to research and understand the potential challenges and limitations of conducting an anesthesia/surgery project in the field (eg, it may not be possible to ship oxygen cylinders and flammable anesthetic gases to some remote locations, so injectable anesthetics may be necessary). Veterinarians involved with wildlife research projects do not need to compromise the quality of care provided, because it is possible to practice excellent medicine in remote field camps with careful advance planning.
Acknowledgments: I thank Dr Dan Mulcahy and Dr Terra Kelly, who procured, organized, and packed the surgery and anesthesia supplies and equipment for the various projects; Dr Greg Golet, who was the lead biologist during both seasons involving pigeon guillemots; and Dr Richard Lanctot, who was the lead biologist on the black oystercatcher project. I thank Kim Trust and Dr Craig Harms, who monitored anesthesia for the first and second pigeon guillemot seasons, respectively; and Dr Terra Kelly, who assisted with surgery and anesthesia duties in the oystercatcher project. I also thank the following individuals who assisted with various parts of the field projects: Kelsey Sullivan and Alison McKnight, two very skilled biologists with whom I worked all 3 seasons; and Doug Alcorn, Laura Ballock, Emily Bernhardt, Julian Fischer, Adrian Gall, Laura Ganis, Amy Hahn, Jim Hamon, Christopher Kuntzsch, Michael Litzow, Angela Palmer, Tanya SandbergDiment, Oliver Sternicki, Mike Walgren, and Joe McClung. This study was part of a larger study supported by the Exxon Valdez Oil Spill Trustee Council and the US Fish and Wildlife Service; however, the author's conclusions are her own and do not necessarily reflect the views or position of the funding agencies.

\section{References}

1. Golet GH, Seiser PE, McGuire AD, et al. Longterm direct and indirect effects of the Exxon Valdez oil spill on pigeon guillemots in Prince William Sound, Alaska. Mar Ecol Prog Ser. 2002;241:287-302.

2. Degernes LA, Harms CA, Golet GH, Mulcahy DM. Anesthesia and liver biopsy techniques for pigeon guillemots (Cepphus columba) suspected of exposure to crude oil in marine environments. J Avian Med Surg. 2002;16:291-299. 